\title{
A Hidrovia Tietê-Paraná e o Porto Intermodal de Pederneiras-SP: transporte de cargas e participação do capital privado
}

Nelson Fernandes Felipe Junior* Márcio Rogério Silveira ${ }^{* *}$

\section{Resumo}

A mundialização do capital e a expansão dos meios de produção conduzem a um aumento progressivo da divisão do trabalho e das contradições sociais, diante de uma dialética intrínseca aos diferentes espaços geográficos. A acumulação de capitais no limiar do século XXI se baseia em processos de reordenamentos, como os de caráter técnico-científico-informacional e público-privado, resultando num desenvolvimento desigual entre os diferentes territórios, sendo que as ações, articulações e investimentos do capital privado são fatores que possibilitam a existência desses antagonismos. Assim, o Porto Intermodal de Pederneiras-SP, que integra o sistema de circulação e transportes da Hidrovia Tietê-Paraná, representa a utilização da intermodalidade visando não somente a otimização do transporte de mercadorias, mas também a integração de diferentes territórios.

Palavras-chave: Transporte fluvial; Cargas; Intermodalidade; Infra-estruturas; logística.

\footnotetext{
* Mestrando em Geografia - FCT/UNESP - Presidente Prudente (nelfelipejr@bol.com.br).

** Professor Doutor da UNESP - Ourinhos (marcio@ourinhos.unesp.br).
}

Geosul, Florianópolis, v. 24, n. 47, p 29-48, jan./jun. 2009 
FELIPE JR., N.F. \& SILVEIRA, M.R. A Hidrovia Tietê-Paraná e o Porto ...

The Tietê-Paraná Waterway and the Intermodal Harbor of

Pederneiras-SP: transportation of loads and private capital participation

\begin{abstract}
The mundialization of capital and the growth of productive forces lead to a progressive increase of the work division and social antagonisms, in front of a dialectic common to different geographic spaces. The capital accumulation in the beginning of the $21^{\text {st }}$ century is based on the reorganization of technical, scientific, informative and public private proceedings, resulting in an unequal development among the different territories. The actions, articulations and investments on private capital are factors that enable the existence of these contradictions. Thus, the Intermodal Harbor of Pederneiras-SP, which links the waterway Tietê-Paraná circulation and transportation systems, represents the use of the intermodality aiming not only the improvement on merchandises transportation, but also the integration of different territories.
\end{abstract}

Key words: Fluvial transport; Loads; Intermodality; Substructure; logistic.

\title{
Introdução
}

$\mathrm{O}$ atual processo de internacionalização da economia e dos mercados é conduzido em função dos interesses do grande capital, com destaque para a tecnocracia. Compreender a contemporaneidade significa considerar diversos elementos, aspectos e agentes em sua complexidade, visto que estão imbricados e se complementam, como os políticos, econômicos, financeiros, sociais e ambientais. A mundialização do capital (CHESNAIS, 1996) e o advento do período técnico-científicoinformacional (SANTOS, 2002) determinam sobremaneira as mudanças nas relações entre o local, regional, nacional e global. Ademais, a expansão do sistema de circulação material e imaterial e a formação de redes e fluxos a partir de fixos possibilitam o 
FELIPE JR., N.F. \& SILVEIRA, M.R. A Hidrovia Tietê-Paraná e o Porto ...

deslocamento a grandes distâncias e modificam a divisão social e territorial do trabalho.

O território apresenta três características que convivem dialeticamente e em conjunto construindo um espaço de domínio do grande capital privado, quais sejam: a produção/transformação do espaço e da paisagem, as marcantes e constantes relações econômicas, financeiras, sociais e do homem com o meio, além das especializações funcionais e produtivas, resultantes da facilidade de comunicação e transportes. Dessa maneira:

A produção do espaço é resultado da ação dos homens agindo sobre o próprio espaço, através dos objetos, naturais e artificiais. Cada tipo de paisagem é a reprodução de níveis diferentes de forças produtivas, materiais e imateriais, pois o conhecimento também faz parte do rol das forças produtivas (SANTOS, 1996, p. 64).

Diante desse contexto, para garantir a fluidez e mobilidade no espaço é fundamental a construção e readequação da materialidade (infra-estruturas), bem como a otimização da gestão e da logística. As transformações decorrentes da acumulação flexível levam a necessidade de novas estratégias e flexibilidades por parte das empresas, bem como a reorganização interna visando concorrer de forma competitiva no mercado. Assim, destaca-se a aquisição de novas tecnologias, produção do tipo just in time, marketing, novos designs e adaptações de acordo com a lógica do mercado (BENKO, 1996).

O sistema hidroviário Tietê-Paraná e, mais especificamente, o Porto Intermodal de Pederneiras-SP possibilitam - de maneira racional, planejada e com investimentos - a mobilidade e a circulação formando redes e fluxos materiais no espaço, além de contribuírem com a integração do território nacional, mais precisamente, entre o Centro-Oeste e Sudeste. A utilização do transporte hidroviário é resultado da combinação de diferentes fatores e elementos, como os naturais, técnicos, materiais e organizacionais. As inter-relações entre os elementos naturais (físicos e biológicos) e as atividades humanas permitem uma visão 
FELIPE JR., N.F. \& SILVEIRA, M.R. A Hidrovia Tietê-Paraná e o Porto ...

integrada do espaço geográfico. Assim, a teoria das combinações geográficas (CHOLLEY, 1964) diante da temática do transporte hidroviário é essencial, pois considera em conjunto o meio físico (cursos fluviais), os objetos presentes no espaço e as ações da sociedade.

Diante disso, destaca-se o Porto Intermodal de PederneirasSP no escoamento de cargas, pois interliga diversos espaços, fomenta a produção e facilita a distribuição das mercadorias aos centros de demanda. Está inserido no sistema hidroviário TietêParaná e, através da intermodalidade, soja e farelo são transportados pela hidrovia, representando novas alternativas para a reestruturação da matriz de transportes no Brasil e, sobretudo, no Estado de São Paulo. Ademais, cria-se uma inter-relação entre os dois terminais privados existentes na área portuária com todo município, visto que representam possibilidades, dentre vários aspectos, para criação de novos empregos e renda à população.

A partir do exposto, o trabalho está estruturado em três partes, quais sejam: a primeira realiza uma discussão acerca do transporte hidroviário interior e da intermodalidade; a segunda apresenta uma caracterização geral da Hidrovia Tietê-Paraná e do transporte de cargas; e a terceira trata da participação do capital privado no Porto Intermodal de Pederneiras-SP, com as empresas Torque Ltda, Caramuru Alimentos Ltda, Louis Dreyfus Commodities Brasil S.A. e Comercial Quintella Comércio e Exportação S.A.

\section{Transporte hidroviário interior e intermodalidade}

Diante do contexto de mundialização do capital (CHESNAIS, 1996) e das inovações tecnológicas se faz necessário ter uma visão permeada pela dialética, contradições e alianças entre o poder público e o capital privado, considerando as inter-relações entre os indivíduos, instituições e do homem com o meio. A expansão do sistema de circulação e transportes e a formação de redes e fluxos proporcionam uma maior mobilidade no espaço e modificam a divisão social e territorial do trabalho. Para garantir a 
FELIPE JR., N.F. \& SILVEIRA, M.R. A Hidrovia Tietê-Paraná e o Porto ...

fluidez material e imaterial é fundamental a construção e readequação das infra-estruturas, bem como a otimização da gestão e da logística. As transformações das últimas décadas levaram a uma maior especialização funcional dos espaços, além da necessidade das empresas se reorganizarem visando concorrer de forma competitiva no mercado.

Parte da produção agrícola nacional é voltada ao mercado externo (commodities), refletindo o processo de adesão à internacionalização dos mercados. A agricultura no Brasil se caracteriza, cada vez com mais intensidade, pela lógica da modernização que impõe a necessidade da exportação. A produção voltada ao mercado externo contribui com o superávit da balança comercial brasileira e com o aumento das receitas do Estado, visto que são cobrados vários tributos desde a produção até a exportação das mercadorias. Assim, infere-se que há vários espaços agrícolas dentro do território nacional muito integrados e articulados à economia internacional, sobretudo aos grandes mercados, como Estados Unidos, Europa e Ásia.

O transporte fluvial, em comparação ao ferroviário e, sobretudo, ao rodoviário, apresenta as seguintes especificidades e vantagens: do ponto de vista econômico, o baixo custo do frete de transporte e a grande capacidade de cargas; do ponto de vista natural, um sistema que é menos poluente e agressor ao meio ambiente; do estrutural, necessita da intermodalidade para melhor funcionamento e, em relação ao escoamento, apresenta baixa velocidade e maior constância ao longo do trajeto, sendo vantajoso àquelas mercadorias que demoram a perecer, como minérios, fertilizantes, combustíveis, areia, madeira, grãos etc.

Uma análise mais apurada da utilização do modal hidroviário e do sistema intermodal evidencia um cenário de subutilização das hidrovias fluviais, com sistemas de gestão, infraestruturas, organização e logística de navegação ainda incipientes e precários em grande parte dos casos. A hidrovia Tietê-Paraná apesar de ter implantado importantes melhorias na base física e na logística, ainda carece de investimentos e projetos para que o 
FELIPE JR., N.F. \& SILVEIRA, M.R. A Hidrovia Tietê-Paraná e o Porto ...

funcionamento e gestão possam ser otimizados e, por conseguinte, fomentar o transporte de cargas no Estado de São Paulo.

$\mathrm{O}$ debate acerca da reestruturação da matriz de transportes no Brasil se torna imprescindível ainda mais quando se analisa a configuração territorial brasileira marcada pelas heterogeneidades, pela escassez de investimentos e pela despreocupação com regiões que se encontram à mercê do desenvolvimento. Assim, é notório que o Brasil possui uma grande dimensão territorial, com grandes diversidades socioeconômicas, com uma desigual distribuição de densidades tecnológicas e de infra-estruturas, além de uma capacidade heterogênea de assegurar a circulação material e imaterial no espaço.

A utilização de hidrovias e da intermodalidade para escoamento de cargas a longas distâncias ainda é incipiente no Brasil. No que tange a Hidrovia Tietê-Paraná, esta se expandiu a partir da segunda metade da década de 1990, com novos e maiores investimentos realizados pelo capital privado, podendo-se destacar o surgimento de terminais e melhorias nas infra-estruturas e na base tecnológica. Tal fato fomentou o transporte fluvial e a multimodalidade no Estado de São Paulo.

A intermodalidade consiste no uso de mais de um modo de transporte na movimentação de cargas e/ou pessoas, aproveitandose dos aspectos favoráveis de cada modal, de maneira que o resultado final seja a otimização do deslocamento no espaço. Iniciativas públicas e privadas com o objetivo de ampliar a capacidade de transporte de cargas pela hidrovia são necessárias no sentido de integrá-la aos demais tipos de transportes, mediante a construção de terminais intermodais. Um porto trimodal, como o de Pederneiras-SP, permite o escoamento de cargas a partir de três modais diferentes: rodoviário, ferroviário e hidroviário. Os modais não competem entre si, e sim, há cooperação entre eles, contribuindo para o aumento do volume de cargas transportadas para o mercado externo via portos de exportação, como o Porto de Santos-SP, por exemplo. Cabe ressaltar que cada modal 
FELIPE JR., N.F. \& SILVEIRA, M.R. A Hidrovia Tietê-Paraná e o Porto ...

desempenha o papel de transportar os produtos mais adequados às suas características operacionais.

Realizar parcerias entre o poder público e o capital privado (PPPs) é fundamental para reestruturar o sistema de circulação e transportes no Brasil, estimulando a intermodalidade e, por conseguinte, a cooperação entre os modais. Ademais, verifica-se a opção de várias empresas pelo escoamento de cargas via multimodalidade, o que contribui para a formação de redes hidrorodo-ferroviárias no espaço, como no caso do Porto de Pederneiras-SP. Diante disso, é possível dizer que o uso do território se torna mais corporativo e privado, tanto no meio rural quanto no espaço urbano, despontando a figura dos grandes agroindustriais e dos tecnocratas, num período de tendência à monopolização/oligopolização dos mercados e especializações produtivas e funcionais.

O conteúdo das ações do Estado e do capital no espaço reflete a produção e a dinâmica econômica interna, na medida em que se acentuam os investimentos, a utilização de capitais produtivos e as bases tecnológicas. Em decorrência, verifica-se uma acentuação dos fluxos materiais e imateriais, contribuindo sobremaneira para a expansão da economia, ao mesmo tempo em que articula e integra diversos territórios, agentes e instituições dentro do capitalismo global (FURTADO 2000).

As grandes corporações capitalistas impõem a sua lógica, influenciando o comportamento do poder público e de outras empresas que dependem de sua existência a fim de adequar a dinâmica territorial e econômica aos seus interesses, com o objetivo de obter maior capacidade e competitividade no mercado, bem como aumentar a produção e o lucro. Isto é, evidencia-se uma valorização demasiada do grande capital internacional pelo Estado, em detrimento de políticas públicas e de um projeto de fomento ao desenvolvimento socioeconômico e socioambiental endógeno.

A ideologia neoliberal - que é incorporada pelo Estado brasileiro no governo Collor e intensificada durante os dois mandatos de Fernando Henrique Cardoso nos anos de 1990 
FELIPE JR., N.F. \& SILVEIRA, M.R. A Hidrovia Tietê-Paraná e o Porto ...

enfraquece o planejamento regional e nacional realizado pelo Estado, ao mesmo tempo em que se verifica uma ausência de projeto de desenvolvimento. As privatizações e concessões foram realizadas de maneira incorreta, segundo as propostas de Ignácio Rangel (2005), e refletem a busca pela redução dos gastos públicos.

A saída rangeliana seria a concessão de serviços públicos à iniciativa privada e está ligada à idéia de desenvolvimento nacional integrado a partir do Estado-planejador e que estabelece um projeto nacional. Esta não se refere à transferência desordenada de empresas com capacidade ociosa à iniciativa privada, pois isto não gera resultados macroeconômicos significativos. O capital privado, diante disso, não é estimulado a realizar maiores investimentos, já que esta se encontra superinvestida. Não se faz necessário maiores recursos destinados a equipamentos e máquinas, o que elucida a simples transferência de patrimônio, e não é representativo do ponto de vista nacional e macroeconômico.

A proposta de Rangel se baseia na transferência à iniciativa privada das empresas que se encontram estranguladas, com capacidade antiociosa, isto é, com demanda de maiores investimentos. A transferência se dá com o objetivo de fomentar maiores recursos aos setores subinvestidos e obsoletos. Assim, os setores que demandam maior participação do capital privado são os serviços de utilidade pública (transportes, energia e saneamento), já que se encontram sub-capitalizados.

Não obstante, venderam-se empresas do setor petroquímico, siderúrgico, extrativo, entre outros, não resolvendo a questão e o problema macroeconômico nacional. Houve apenas uma transferência de patrimônio do público para o privado, contradizendo o pensamento de Rangel. Quem disponibiliza, desde os anos de 1980, capacidade de levantar recursos e realizar maiores investimentos é o setor privado, com destaque para as indústrias de base. Todavia, enfraqueceu-se a capacidade de praticar novos investimentos nessa área produtiva, visto que a atividade se encontra superinventida ou "antiestrangulada". 
FELIPE JR., N.F. \& SILVEIRA, M.R. A Hidrovia Tietê-Paraná e o Porto ...

Dessa maneira, apresenta-se uma alternativa extremamente viável à superação dos obstáculos ao desenvolvimento nacional, principalmente no que tange a modernização e otimização das infra-estruturas, imprescindíveis à economia brasileira. Criam-se novas oportunidades de investimentos para a iniciativa privada, na expectativa de reduzir os recursos aplicados no sistema financeiro e no mercado especulativo.

A concessão de serviços públicos à iniciativa privada não significa isentar o Estado de suas funções e responsabilidades políticas, administrativas, econômicas, financeiras e de planejamento, ou seja, isto não representa o pensamento neoliberal, muito pelo contrário, cabe ao poder público as seguintes funções e poderes, quais sejam: dizer como e onde investir, quais tarifas devem ser cobradas, impor metas e prazos a serem cumpridos, fiscalização das ações e medidas adotadas pelo concessionário, poder concedente e credor hipotecário, entre outros.

Diante do contexto de globalização, atribuir relevância ao sistema de circulação e transportes é fundamental para fomentar as interações espaciais (CORRÊA, 1997), a integração territorial, o comércio, a produção e o escoamento de mercadorias, fortalecendo as regiões já dinâmicas e fomentando o crescimento econômico nos espaços permeados pelo atraso. Assim, as hidrovias e a intermodalidade são alternativas que devem ser melhor exploradas no Brasil, recebendo maiores investimentos e iniciativas para aumentar e qualificar suas infra-estruturas e elevar o fluxo de meios circulantes no espaço.

$\mathrm{O}$ sistema hidroviário e a multimodalidade vem se destacando diante da necessidade de reestruturação da matriz de transporte de cargas no Brasil, com o objetivo de fomentar toda cadeia produtiva e, por conseguinte, criar novos empregos e renda à população. Portanto, a Hidrovia Tietê-Paraná aparece como uma alternativa para o desenvolvimento, pois a otimização das infraestruturas e da logística pode contribuir com a economia e com toda sociedade. 
FELIPE JR., N.F. \& SILVEIRA, M.R. A Hidrovia Tietê-Paraná e o Porto ...

\section{A Hidrovia Tietê-Paraná e o transporte de cargas}

Percorrendo grande parte do território paulista no sentido leste-oeste, o rio Tietê desemboca no rio Paraná. A união dos dois cursos fluviais constitui a Hidrovia Tietê-Paraná, possuindo 2400 $\mathrm{km}$ de extensão $(1600 \mathrm{~km}$ referentes ao Rio Paraná e $800 \mathrm{~km}$ abrangendo os rios Piracicaba e Tietê).

A utilização dos rios Tietê e Paraná como vias navegáveis vem sendo proposta desde a década de 1950, quando um grupo de engenheiros iniciou estudos para o aproveitamento múltiplo desses dois cursos fluviais. No ano de 1967, foi firmado convênio entre os governos Federal e do Estado de São Paulo para prosseguir com as obras de navegação no Sistema Tietê-Paraná, criando-se a CENAT (Comissão Executiva de Navegação nos Rios Tietê-Paraná). Em 1974, foi firmado novo convênio envolvendo a CESP (Companhia Energética de São Paulo) para conclusão das obras de navegação fluvial. Dessa maneira, foram criadas as barragens de Barra Bonita, Bariri, Ibitinga e Promissão, no rio Tietê, e Ilha Solteira e Jupiá, no rio Paraná.

O início do funcionamento da hidrovia é recente, pois ocorreu na medida em que foram concluídas as diversas obras de aproveitamento múltiplo dos rios Tietê e Paraná. A hidrovia do Tietê começou em 1981 com o transporte regional de cana-deaçúcar realizado pela Usina Diamante (produção de açúcar e álcool), localizada no município de Jaú-SP. Em 1991, iniciou-se o de longa distância através de todo rio Tietê e no Tramo Norte do rio Paraná, ligados pelo canal Pereira Barreto, possibilitando que a navegação alcançasse o Sul do Estado de Goiás e o Oeste do Estado de Minas Gerais.

No contexto da Hidrovia Tietê-Paraná, pode-se destacar o Estado de São Paulo, pois grande parte do seu tramo se encontra nesse território, a qual é servida por rodovias e ferrovias, e está no centro de um conjunto de cidades de destaque no estado, como Campinas, Piracicaba, Ribeirão Preto, São José do Rio Preto, Araçatuba, Bauru e Sorocaba, sendo pólos industriais, comerciais e de serviços. Relevante é atentar para o eixo Bauru-Jaú, pois há uma 
FELIPE JR., N.F. \& SILVEIRA, M.R. A Hidrovia Tietê-Paraná e o Porto ...

estrutura hidro-rodo-ferroviária que desempenha importante papel no transporte intermodal de cargas, por meio do porto da cidade de Pederneiras-SP.

Os sistemas hidroviário, ferroviário e a multimodalidade vêm se destacando diante da necessidade de racionalização do transporte de cargas no Brasil. Dentro desse contexto, insere-se a Hidrovia Tietê-Paraná e seus terminais, como os de Pederneiras-SP, que contribuem com a articulação e integração entre o Centro-Oeste e o Estado de São Paulo, através do transporte de soja e farelo dos Estados de Goiás e Mato Grosso até o Porto de Santos-SP.

Uma análise mais apurada da utilização do modal hidroviário evidencia um cenário, infelizmente, de subutilização dos cursos fluviais, apresentando infra-estruturas precárias e obsoletas, organização e logística de navegação ainda incipientes em grande parte dos casos, além da falta de projetos por parte do Estado e alianças entre o poder público e o capital privado que fomentem o sistema hidroviário e a intermodalidade no país. Com o intuito de superar a saturação do sistema rodoviário em território nacional e também do Custo Brasil, extremamente prejudiciais ao crescimento econômico, faz-se necessário romper com a estrutura exacerbadamente rodoviária existente no país.

Atribuir relevância à Hidrovia Tietê-Paraná e ao Porto Intermodal de Pederneiras-SP é condição para melhor articular espaços de produção e de demanda, ao mesmo tempo em que possibilita a intermodalidade, ou seja, a cooperação entre os modais hidroviário e ferroviário. Sistemas hidroviários são novas alternativas que facilitam e estimulam a integração de diversos territórios, os fluxos materiais e as reestruturações na lógica organizacional e logística dos transportes no Estado de São Paulo.

Um terminal fluvial, assim como um terminal marítimo, pode ser entendido, de forma geral, como um arranjo físico que compreende diversas obras de engenharia importantes sob o ponto de vista econômico, capaz de atender satisfatoriamente as seguintes funções:

- Carregamento e descarregamento das embarcações que utilizam as facilidades portuárias; 
FELIPE JR., N.F. \& SILVEIRA, M.R. A Hidrovia Tietê-Paraná e o Porto ...

- Estocagem temporária da carga desembarcada ou a ser embarcada;

- Distribuição da carga (via ferrovia, rodovia e hidrovia) para os mercados de demanda;

- Processamento industrial e produção.

A hidrovia estimula a produção e a competitividade das mercadorias da sua região de influência e promove a integração dos modais (intermodalidade). Outras são as vantagens quando o transporte fluvial é comparado com os demais meios de circulação de mercadorias, como a necessidade de investimentos menores do que as rodovias e ferrovias, baixo preço do frete, grande capacidade de escoamento de cargas, facilidades para o deslocamento de cargas volumosas e menor degradação do meio ambiente.

A integração entre hidrovia, ferrovia e rodovia formando um sistema multimodal de transporte garante uma circulação contínua e mais viável, desde a origem até o destino das mercadorias. Ademais, cabe ressaltar que o transporte fluvial é um fator de minimização do custo, resultando, por conseqüência, na queda do valor das mercadorias e no aumento da competitividade dos produtos brasileiros no mercado internacional, ou seja, acaba por beneficiar tanto o capital privado quanto o Estado, mediante uma balança comercial favorável. A otimização da Hidrovia TietêParaná requer uma logística de qualidade, terminais adequados para movimentação de cargas, instalação de modernos equipamentos de transbordo, armazéns, silos e entroncamentos multimodais, constituindo uma infra-estrutura satisfatória para o pleno funcionamento do sistema.

Tabela 1: Dinâmica do transporte de cargas no Brasil (em \%)

\begin{tabular}{|l|c|c|c|}
\hline \multicolumn{1}{|c|}{ Modais } & $\mathbf{1 9 8 5}$ & $\mathbf{1 9 9 9}$ & $\mathbf{2 0 0 6}$ \\
\hline Rodoviário & 57,6 & 61,8 & 60,0 \\
\hline Ferroviário & 23,6 & 19,5 & 20,1 \\
\hline Hidroviário & 14,3 & 13,8 & 14,3 \\
\hline Outros & 4,5 & 4,9 & 5,6 \\
\hline
\end{tabular}

Fonte: Geipot. 
FELIPE JR., N.F. \& SILVEIRA, M.R. A Hidrovia Tietê-Paraná e o Porto ...

Tabela 2: Principais cargas escoadas pela Hidrovia Tietê-Paraná em 2005 (em toneladas)

\begin{tabular}{|c|c|}
\hline Produtos & Quantidade \\
\hline Soja & $937 \mathrm{mil}$ \\
\hline Cana & $807 \mathrm{mil}$ \\
\hline Areia & $681 \mathrm{mil}$ \\
\hline Milho & $266 \mathrm{mil}$ \\
\hline Madeira & $166 \mathrm{mil}$ \\
\hline Outros & 248 mil \\
\hline Total & 3,5 milhões \\
\hline
\end{tabular}

Fonte: Departamento Hidroviário do Estado de São Paulo, 2006.

Assim, infere-se que o modal rodoviário possui grande predomínio no que tange ao transporte de cargas no Brasil, já os modais ferroviário e hidroviário ainda estão muito aquém das possibilidades existentes, devido à inexistência de uma política de transportes estratégica. Essa opção rodoviária ainda é muito forte no país, mesmo com as vantagens oferecidas pelos outros modais.

Diante do destaque econômico e financeiro do Estado de São Paulo, surge a necessidade de um sistema de circulação e transportes mais eficiente. Potencializar o funcionamento e a logística da Hidrovia Tietê-Paraná e do Porto Intermodal de Pederneiras-SP é uma alternativa para que novas estratégias e investimentos públicos e privados fomentem o desenvolvimento de vários municípios paulistas e as interações espaciais (CORRÊA, 1997).

\section{O Porto Intermodal de Pederneiras-SP e a participação do capital privado}

O início das operações do Porto de Pederneiras-SP ocorreu em 1994, com a construção de um estaleiro pela empresa Torque Ltda para construção de chatas. Todavia, é a partir do ano de 2000 que o terminal inicia uma nova fase de funcionamento, com a construção da rodovia vicinal que liga a área urbana de 
FELIPE JR., N.F. \& SILVEIRA, M.R. A Hidrovia Tietê-Paraná e o Porto ...

Pederneiras-SP ao Porto Intermodal, e a extensão da linha férrea, com um terceiro trilho, que pertence a América Latina Logística (ALL). A construção dessa linha foi de suma relevância, pois acabou com o problema da incompatibilidade de bitolas que prejudicavam o escoamento de mercadorias para o Porto de Santos-SP.

Com esse potencial, o Porto Intermodal de Pederneiras-SP se caracteriza como um fixo que contribui para o funcionamento do sistema Tietê-Paraná, visto que a multimodalidade facilita a circulação e transporte de cargas, interligando diferentes espaços. $\mathrm{O}$ porto se apresenta como um ponto nodal no que tange ao escoamento de soja e farelo pela hidrovia e que chegam ao Porto de Santos-SP, com a participação direta do capital privado na logística de funcionamento do sistema intermodal, quais sejam: as empresas Torque Ltda, Caramuru Alimentos Ltda, Louis Dreyfus Commodities Brasil S.A. e Comercial Quintella Comércio e Exportação S.A.

A empresa Caramuru Alimentos Ltda se dedica à produção de grãos e farelos, armazenagem, extração e refino de óleos especiais de soja, milho, girassol, canola etc. Com capitais e controle acionário nacionais, a empresa atua no Porto Multimodal de Pederneiras-SP desde 2001, armazenando soja e farelo e transportando as mercadorias via ferrovia até o Porto de Santos-SP em cooperação com a MRS Logística (esta empresa recebeu a permissão da ALL para realizar o transporte de Pederneiras-SP até Santos-SP). A Caramuru é uma empresa brasileira com grande atuação e destaque no ramo alimentício e nas exportações de commodities.

A empresa Caramuru atua no Porto Intermodal em cooperação com o Grupo Torque Ltda, já que esse se encarrega de transportar grãos de soja e farelo pela Hidrovia Tietê-Paraná através da Empresa Paulista de Navegação. O Grupo Torque atua em vários ramos, como metalurgia e, principalmente, transporte hidroviário. Possui capitais e controle acionário nacionais e se destaca como a principal empresa de transporte da Hidrovia Tietê- 
FELIPE JR., N.F. \& SILVEIRA, M.R. A Hidrovia Tietê-Paraná e o Porto ...

Paraná. A empresa é responsável por toda parte logística e operacional ligada ao transporte fluvial de cargas, descarregamento dos comboios, condução das cargas até o armazém, e daí para os vagões que escoam a carga até o Porto de Santos-SP. Assim, grande parte da infra-estrutura existente - comboios, chapas de retirada da soja e farelo das chatas, esteiras que conduzem a carga até o armazém e, posteriormente, até os vagões, juntamente com o estaleiro para construção de barcaças - pertencem a Torque. Por sua vez, as mercadorias, o armazém com capacidade para estocar 30 mil toneladas de soja e farelo e cerca de 115 vagões pertencem a Caramuru.

A produção oriunda do Estado de Goiás é transportada até o município de São Simão-GO via rodovia. No Porto de São Simão são carregados os comboios que se deslocam pela Hidrovia TietêParaná até os portos de Pederneiras-SP e Anhembi-SP. Nesse último, a carga é transportada até o Porto de Santos-SP através do modal rodoviário, todavia, no Porto Intermodal de Pederneiras-SP as barcaças com grãos de soja e farelo são descarregadas, a carga é conduzida até o armazém, carregam-se os vagões e via ferrovia a produção é escoada até o Porto de Santos-SP.

Outra empresa que se encontra na área portuária do município de Pederneiras-SP é a Louis Dreyfus Commodities Brasil S.A. O grupo Louis Dreyfus, fundado por Leopold LouisDreyfus, em 1851, é um conglomerado controlado pela holding S.A. Louis Dreyfus \& CIE, sediada em Paris, França. A holding é propriedade exclusiva da família Louis-Dreyfus. O grupo atua em diversos ramos, quais sejam: na comercialização internacional de commodities agrícolas, extração de madeira, produção de energia, esmagamento e refino de sementes oleaginosas, produção de açúcar e álcool, processamento de frutas cítricas, exploração, refino e comercialização de petróleo e gás natural, telecomunicações, administração de frotas de navios oceânicos, projetos imobiliários e serviços financeiros.

Com capitais e controle acionário internacionais (franceses), esse grupo é um dos maiores do mundo no que tange a 
FELIPE JR., N.F. \& SILVEIRA, M.R. A Hidrovia Tietê-Paraná e o Porto ...

comercialização de commodities agrícolas. A unidade da empresa instalada no Porto Multimodal de Pederneiras-SP realiza as atividades de descarregamento dos comboios fluviais e armazenamento da soja em dois silos e um armazém, totalizando uma capacidade de armazenar 13 mil toneladas de grãos de soja. Ademais, operacionaliza em cooperação com a MRS Logística, responsável por escoar os grãos do terminal até o Porto de SantosSP. A Louis Dreyfus é uma empresa que atua, principalmente, no ramo de exportações de commodities em vários continentes, como na América do Sul e Europa.

A Louis Dreyfus atua no Porto Intermodal de PederneirasSP em cooperação com a Comercial Quintella Comércio e Exportação S.A., já que é a empresa responsável pelo transporte dos grãos de soja pela Hidrovia Tietê-Paraná. A Comercial Quintella possui capitais e controle acionário nacionais e atua no ramo de transporte fluvial. Juntamente com a Torque Ltda são as duas principais empresas que escoam produtos pela Hidrovia TietêParaná. A Comercial Quintella e a Torque são prestadoras de serviços para as empresas Louis Dreyfus e Caramuru Alimentos, respectivamente.

A produção oriunda dos Estados de Mato Grosso e Goiás é transportada até o município de São Simão-GO via rodovia. No Porto de São Simão-GO são carregadas as barcaças que se destinam pela Hidrovia Tietê-Paraná até o município de Pederneiras-SP via comboios da Comercial Quintella. Chegando no terminal, as barcaças com soja são descarregadas, em seguida as mercadorias são conduzidas até o armazém e silos através de esteiras, e daí até a ferrovia. Por fim, a carga é escoada até o Porto de Santos-SP para ser exportada. Quanto à infra-estrutura da Louis Dreyfus no terminal, tem-se: o centro de descarregamento das barcaças, as chapas de retirada da soja, as esteiras que conduzem os grãos, além de dois silos e um armazém que comportam 13 mil toneladas de soja. Todavia, os comboios que escoam as cargas pela hidrovia pertencem a Comercial Quintella. 
FELIPE JR., N.F. \& SILVEIRA, M.R. A Hidrovia Tietê-Paraná e o Porto ...

Tabela 3: Transporte mensal de soja e farelo do Porto Intermodal de Pederneiras-SP para o Porto de Santos-SP, em 2006 (em toneladas)

\begin{tabular}{|c|c|}
\hline Empresas & Quantidade \\
\hline Caramuru & 37,5 mil de soja e farelo \\
\hline Louis Dreyfus & 50 mil de soja \\
\hline
\end{tabular}

Fonte: Caramuru Alimentos Ltda, Louis Dreyfus Commodities Agrícolas S.A. e Torque Ltda.

\section{Considerações finais}

A transformação do espaço e da paisagem está intimamente ligada às práticas econômicas e produtivas, e se delineia de acordo com o interesse dos grupos sociais e econômicos que controlam e possuem as forças produtivas. As ações sociais que visam produção, distribuição e consumo requerem a existência de capitais e bases materiais (tecnologias e infra-estruturas) para sua eficácia e integração entre os centros produtores e mercados consumidores.

O Porto Intermodal de Pederneiras-SP, como sendo parte integrante do contexto marcado pelas novas lógicas organizacionais, operacionais e produtivas do capitalismo atual, se apresenta como um espaço estratégico para o transporte de mercadorias no território, isto é, ele assegura a articulação entre o local e o global, os fluxos materiais mediante a formação de redes, a intermediação entre produtor e mercado, além da reprodução do capital. Este acaba por contribuir para a especialização produtiva dos territórios e suas infra-estruturas são pré-requisitos para a existência de fluxos de mercadorias.

A logística se torna imprescindível para a otimização da intermodalidade, pois representa as estratégias que abarcam todas as funções cabíveis aos terminais privados, como gestão, transporte, manutenção, armazenagem e transbordo das cargas. Assim, tem-se uma estreita ligação entre os fluxos materiais e imateriais (comunicação e informação), intensificando, por conseguinte, as interações espaciais e a integração econômica. 
FELIPE JR., N.F. \& SILVEIRA, M.R. A Hidrovia Tietê-Paraná e o Porto ...

Assim, verifica-se que a lógica das empresas Torque Ltda, Caramuru Alimentos Ltda, Louis Dreyfus Commodities Brasil S.A. e Comercial Quintella Comércio e Exportação S.A. está em consonância às novas exigências e imposições da economia flexível, da globalização e do capitalismo no início do século XXI, e a presença destas no município de Pederneiras-SP acaba resultando em vantagens para todos (empresas, poder público, economia e sociedade). A presença das instituições privadas contribui para o crescimento econômico municipal, pois surgem novos empregos (diretos e indiretos) e renda. Soma-se a isso, o fomento do comércio e serviços, aumento do poder de compra da população, além da maior obtenção de receita por parte do poder público municipal e estadual.

Por fim, os reflexos geoeconômicos do sistema hidroviário Tietê-Paraná e da intermodalidade vão além do transporte de mercadorias, visto que através das infra-estruturas e da logística existentes há o aumento da fluidez na articulação inter-regional, com a formação de redes. Ademais, a dinâmica da hidrovia e da multimodalidade tende a uma concentração industrial nos espaços em que se encontram os portos intermodais, formando pontos nodais de circulação de cargas no território.

\section{Referências bibliográficas}

BENKO, G. Economia, espaço e globalização na aurora do século XXI. São Paulo: Hucitec, 1996.

CASTELLS, M. A sociedade em rede. São Paulo: Paz e Terra, 2000.

CHESNAIS, F. A mundialização do capital. São Paulo: Xamã, 1996.

CHOLLEY, A. Observações sobre alguns pontos de vista geográficos. Boletim Geográfico, Rio de Janeiro, v.22, n. 179, p.139-145, 1964. 
FELIPE JR., N.F. \& SILVEIRA, M.R. A Hidrovia Tietê-Paraná e o Porto ...

CORRÊA, R. L. Interações espaciais. In: CASTRO, I. E de; GOMES, P. C da C.; CORRÊA, R. L. (Orgs.) Explorações geográficas. Rio de Janeiro: Bertrand Brasil, 1997, p. 279-318.

FIORI, J. L. Brasil no espaço. Petrópolis: Vozes, 2001.

FURTADO, C. O capitalismo global. São Paulo: Paz e Terra, 2000.

KON, A. Economia industrial. São Paulo: Nobel, 1994.

MARX, K. O capital. São Paulo: Bertrand Brasil, 1987.

MOTOYAMA, S. Tecnologia e industrialização no Brasil. Uma perspectiva histórica. São Paulo: UNESP, 1994.

RANGEL, I. Obras reunidas (vol. 1 e 2). Rio de Janeiro: Contraponto, 2005.

ROCHEFORT, M. Redes e sistemas. São Paulo: Hucitec, 1998.

SANTOS, M. A natureza do espaço. São Paulo: USP, 2002.

SANTOS, M. Metamorfoses do espaço habitado. São Paulo: Hucitec, 1996.

SANTOS, M. Por uma outra globalização. São Paulo: Record, 2002.

SANTOS, M.; SILVEIRA, M. Z. O Brasil: território e sociedade no início do século XXI. Rio de Janeiro e São Paulo: Record, 2001.

SILVA JR, R. F. Geografia de redes e da logística no transporte rodoviário de cargas: fluxos e mobilidade geográfica do capital. Dissertação de Mestrado em Geografia. Presidente Prudente: FCT UNESP, 2004.

SILVEIRA, M. R. A importância geoeconômica das estradas de ferro no Brasil. Tese de Doutorado em Geografia. Presidente Prudente: FCT - UNESP, 2003. 
FELIPE JR., N.F. \& SILVEIRA, M.R. A Hidrovia Tietê-Paraná e o Porto ...

SMITH, N. Desenvolvimento desigual. Rio de Janeiro: Bertrand Brasil, 1988.

SPOSITO, E. S. Dinâmica econômica, poder e novas territorialidades. Presidente Prudente: UNESP: GAsPERR, 1999.

SPOSITO, E. S. Produção do espaço e redefinições territoriais. Presidente Prudente: UNESP/ GAsPERR, 2004.

VARGAS, M. A. M. Desenvolvimento regional em questão. São Cristóvão: UFSE: NPGEO, 1999.

WALLERSTEIN, I. M. O sistema mundial moderno. Porto: Afrontamentos, 1974.

Recebido em novembro de 2007 Aceito em setembro de 2008 